\title{
Pretargeted Immuno-PET of Pancreatic Cancer: Overcoming Circulating Antigen and Internalized Antibody to Reduce Radiation Doses
}

\author{
Jacob L. Houghton ${ }^{1,2}$, Brian M. Zeglis ${ }^{3}$, Dalya Abdel-Atti ${ }^{1,2}$, Ritsuko Sawada ${ }^{4}$, Wolfgang W. Scholz ${ }^{4}$, and Jason S. Lewis ${ }^{1,2}$ \\ ${ }^{I}$ Department of Radiology, Memorial Sloan Kettering Cancer Center, New York, New York; ${ }^{2}$ Program in Molecular Pharmacology, \\ Memorial Sloan Kettering Cancer Center, New York, New York; ${ }^{3}$ Department of Chemistry, Hunter College and the Graduate Center \\ of the City University of New York, New York, New York; and ${ }^{4}$ MabVax Therapeutics, San Diego, California
}

$5 \mathrm{~B} 1$ is a fully human, monoclonal antibody that has shown promise for the PET imaging of cancers expressing carbohydrate antigen 19.9 (CA19.9) - a carbohydrate prevalent in cells with aberrant glycosylation and an established effector of metastasis. The long physiologic half-life of the antibody and interference from circulating CA19.9 may increase the time required to generate quality images as well as the risk of radiation exposure to healthy tissues during repeated PET imaging. Pretargeting methodologies are an effective approach to expeditiously acquire PET images, but in this case, the pretargeting approach is complicated by the internalization of $5 B 1$ by CA19.9-expressing cells. We sought to adapt and optimize a pretargeting strategy that exploits the bioorthogonal reaction between transcyclooctene (TCO) and tetrazine (Tz) to overcome these complications. Methods: 5B1 was modified with TCO, and a novel NOTA-PEG - -Tz radioligand was synthesized with the goal of improving on a previously reported analog. BxPC3 and Capan-2 cells were evaluated for their ability to internalize anti-CA19.9 antibodies using a fluorometric assay, and xenografts of the same lines were used for in vivo studies. The pretargeting approach was optimized, and the 2 radioligands were compared using biodistribution and PET imaging in murine models of pancreatic cancer. Results: BxPC3 and Capan-2 cells were shown to rapidly internalize anti-CA19.9 monoclonal antibodies, including 5B1. ${ }^{64} \mathrm{Cu}-\mathrm{NOTA}_{\mathrm{N}} \mathrm{PEG}_{7}-\mathrm{Tz}$ showed improved in vivo pharmacokinetics relative to ${ }^{64} \mathrm{Cu}-\mathrm{NOTA}-\mathrm{Tz}$ using $5 \mathrm{~B} 1-\mathrm{TCO}$ as the targeting vector. PET imaging and biodistribution studies showed that injecting the radioligand $72 \mathrm{~h}$ after the administration of 5B1-TCO resulted in the best uptake $(8.2 \pm 1.7$ percentage injected dose per gram at $20 \mathrm{~h}$ after injection) and tumor-to-background activity concentration ratios. Dosimetry calculations revealed that the pretargeting system produced a greater than 25 -fold reduction in total body radiation exposure relative to ${ }^{89} \mathrm{Zr}$-desferrioxamine5B1. PET/CT imaging in an orthotopic Capan-2 xenograft modelwhich secretes large amounts of CA19.9 and more rapidly internalizes anti-CA19.9 antibodies-showed that this approach is viable even in the difficult circumstances presented by a circulating antigen and internalized targeting vector. Conclusion: The 5B1-TCO and ${ }^{64} \mathrm{Cu}-\mathrm{NOTA}-\mathrm{PEG}_{7}-\mathrm{Tz}$ system evaluated in these studies can delineate CA19.9-positive xenografts in murine models of pancreatic cancer despite the challenges posed by the combination of circulating antigen and internalization of the 5B1-TCO.

\footnotetext{
Received Jul. 16, 2015; revision accepted Oct. 2, 2015.

For correspondence or reprints contact: Jason S. Lewis, Memorial Sloan Kettering Cancer Center, 1275 York Ave., New York, NY 10065.

E-mail: lewisj2@mskcc.org

Published online Oct. 15, 2015.

COPYRIGHT (C) 2016 by the Society of Nuclear Medicine and Molecular Imaging, Inc.
}

Key Words: pretargeting; pancreatic cancer; PET imaging; CA19.9

J Nucl Med 2016; 57:453-459

DOI: 10.2967/jnumed.115.163824

$\mathbf{T}$ he prognosis for patients with pancreatic ductal adenocarcinoma (PDAC) is consistently poor, and PDAC is poised to surpass breast and colorectal cancer in total annual deaths by 2030 (1). A dearth of effective treatment options and the prevalence of understaging and misdiagnosis are 2 of the many factors preventing improvement to the 5-y survival rate, which is about $5 \%$. ${ }^{18} \mathrm{~F}-\mathrm{FDG}$ is the only Food and Drug Administration-approved PET imaging agent, but it has many inadequacies with respect to PDAC (2). However, many recent studies have suggested that the molecular imaging of PDAC-specific biomarkers offers a promising route toward improving outcomes for PDAC patients (3).

Carbohydrate antigen 19.9 (CA19.9)—a ligand for epithelial leukocyte adhesion molecules that is common in tumors with aberrant glycosylation - is a key effector of invasion and metastasis in pancreatic cancer (4). It has been established as one of the most highly expressed biomarkers in PDAC (5,6), and targeting CA19.9 for the PET imaging of PDAC has proven a successful strategy in preclinical models (7-9). That said, targeting CA19.9 is not without its complications: in most clinical cases of PDAC, CA19.9 is secreted into the blood, which can lead to decreased uptake of anti-CA19.9 PET tracers at the tumor tissue from which it originated, increased residence time in the blood, and increased accumulation in nontarget tissues (i.e., liver and spleen). Nonetheless, ${ }^{89} \mathrm{Zr}$-desferrioxamine (DFO)-5B1-a fully human monoclonal antibody ( $\mathrm{mAb}$ ) - has proven to be an extremely promising candidate for anti-CA19.9 immuno-PET imaging (9). However, antibodies directly labeled with long-lived radioisotopes such as ${ }^{89} \mathrm{Zr}$ (halflife, $\sim 3.2$ d) may present unwanted clinical complications: long delays between the injection of radiotracer and optimal imaging times and unnecessarily high radiation dose rates to healthy tissues. Although these elevated radiation doses to healthy organs are not a major issue for 1-time imaging procedures, they become much more of a concern if repeated imaging procedures are necessary. The radiation dose from repeated PET and CT acquisitions can escalate quickly-especially when using an isotope with relatively long half-life — potentially limiting the efficacy of PET for treatment planning and treatment monitoring.

Taking advantage of the rapid and bioorthogonal inverse electron demand Diels-Alder reaction between transcyclooctene (TCO) and tetrazine $(\mathrm{Tz})$ for pretargeted PET can alleviate the aforementioned 
complications (Fig. 1A). It has been shown that combining the specificity and affinity of TCO-conjugated antibodies with the rapid pharmacokinetics of Tz-conjugated small molecules is, in fact, an effective approach (Fig. 1B). Such an approach becomes even more appealing when targeting shed antigens, in which case there is even greater risk for radiation exposure in nontarget tissues. For that reason, 5B1 became a logical candidate for the development of a second-generation, pretargeted PET imaging system. However, previous studies have indicated that $5 \mathrm{~B} 1$ is internalized to some extent on binding to CA19.9 on the cell surface (8). To date, an oftrepeated presupposition regarding pretargeting has been that cell surface persistence is a prerequisite. Yet, we hypothesized that numerous factors may ultimately determine whether a particular antibody may be successfully used for pretargeting, including but not limited to surface persistence, magnitude of uptake in the target tissue, clearance from nontarget tissues, pharmacokinetics of the radioligand, and kinetics of internalization.

Herein, we have sought to determine whether-using TCOconjugated 5B1 as a targeting vector-we could adapt a pretargeting approach to overcome the inherent challenges of targeting CA19.9. We also sought to improve on the pharmacokinetics of the previously reported radioligands by incorporating a polyethyleneglycol (PEG) linker between the Tz and chelator, thereby further reducing the radiation dose and improving image contrast at earlier time points.

\section{MATERIALS AND METHODS}

\section{Reagents and General Procedures}

All experiments involving laboratory animals were performed in accordance with the Memorial Sloan Kettering Institutional Animal Care and Use Committee. Details regarding all reagents and general procedures may be found in the supplemental data (available at http:// jnm.snmjournals.org).

\section{TCO Conjugation}

$5 \mathrm{~B} 1(4.25 \mathrm{mg}, 5.6 \mathrm{mg} / \mathrm{mL})$ in phosphate-buffered saline ( $\mathrm{pH} 6.0)$ was adjusted to $\mathrm{pH} 8.5$ using a sodium bicarbonate solution $(200 \mathrm{mM})$.

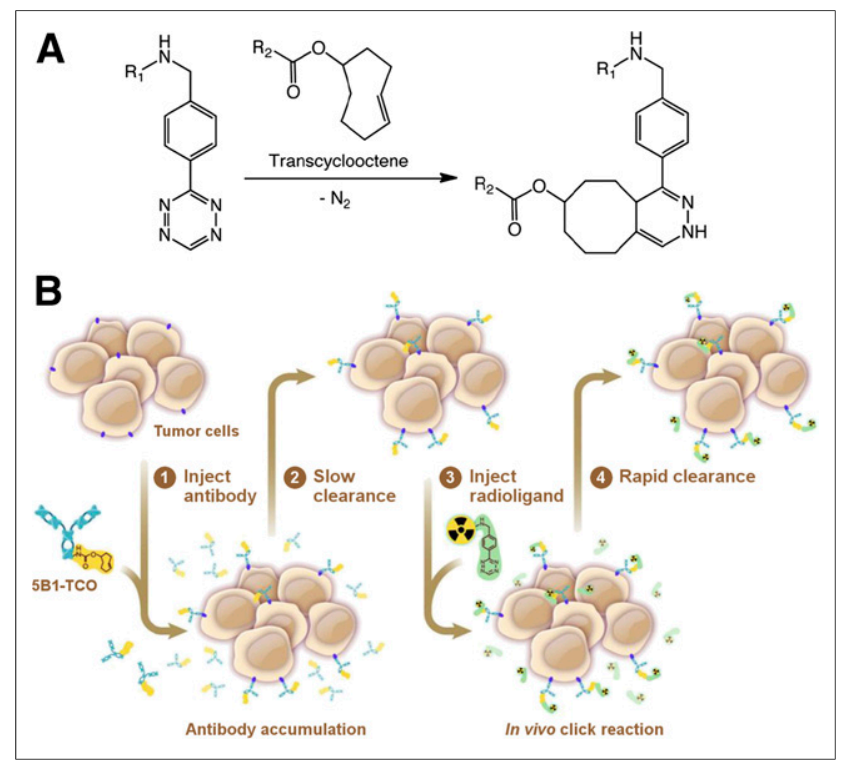

FIGURE 1. Scheme of inverse-demand Diels-Alder reaction between TCO and Tz (A) and pretargeting strategy based on that chemistry that was adapted for PET imaging of PDAC with 5B1 (B) are shown.
Thirty molar equivalents of TCO- $N$-hydroxysuccinimide (NHS) $(25.0 \mathrm{mg} / \mathrm{mL}, 94 \mathrm{mM})$ in $N, N$-dimethylformamide were added. The reaction was incubated at $37^{\circ} \mathrm{C}$ for $90 \mathrm{~min}$ before purification with a PD10 desalting column (GE Healthcare) into sterile $0.9 \%$ saline solution for injection. A nonspecific human IgG-TCO was modified in an identical fashion for use in control experiments.

\section{Synthesis and Radiolabeling of Radioligands}

NOTA-Tz and ${ }^{64} \mathrm{Cu}-\mathrm{NOTA}-\mathrm{Tz}$ were synthesized and prepared as previously described (10). The synthesis of NOTA-PEG $-\mathrm{Tz}$ and radiolabeling to yield ${ }^{64} \mathrm{Cu}-\mathrm{NOTA}-\mathrm{PEG}_{7}-\mathrm{Tz}$ are described in the supplemental data.

\section{Internalization of 5B1 by $\mathrm{BxPC} 3$ and Capan-2 Cells}

$5 \mathrm{~B} 1$ and 2 other human control mAbs-7E3G3, an engineered, highaffinity anti-CA19.9 IgG3 antibody derived from an IgM parent antibody, and $1 \mathrm{~A} 11 \mathrm{G} 3$, a human antiglobo $\mathrm{H}$ antibody - were used to evaluate the internalization of 5B1 (Fig. 2). 5B1 was directly labeled with pHAb amine reactive dye (pHAb-SE; Promega), following the manufacturer's instructions. Additionally, a $\mathrm{F}\left(\mathrm{ab}^{\prime}\right)_{2}$ fragment of a goat, antihuman antibody (Jackson Laboratories) was labeled in the same manner to generate a reagent that could be used with unlabeled antibodies. Unlabeled primary antibody was premixed with the $\mathrm{F}\left(\mathrm{ab}^{\prime}\right)_{2}$-pHAb at a $1: 1$ molar ratio and incubated for $20 \mathrm{~min}$ at room temperature to generate the $5 \mathrm{~B} 1-\mathrm{F}\left(\mathrm{ab}^{\prime}\right)_{2^{-}}$ $\mathrm{pHAb}, 7 \mathrm{E} 3 \mathrm{G} 3-\mathrm{F}\left(\mathrm{ab}^{\prime}\right)_{2}-\mathrm{pHAb}$, and 1A11G3-F( $\left(\mathrm{ab}^{\prime}\right)_{2}-\mathrm{pHAb}$ complexes. The mAb-F $\left(\mathrm{ab}^{\prime}\right)_{2}$-pHAb complexes, directly labeled $5 \mathrm{~B} 1-\mathrm{pHAb}$, or the antihuman $\mathrm{F}\left(\mathrm{ab}^{\prime}\right) 2$-pHAb alone was added to $0.5 \times 10^{6}$ cells per sample of

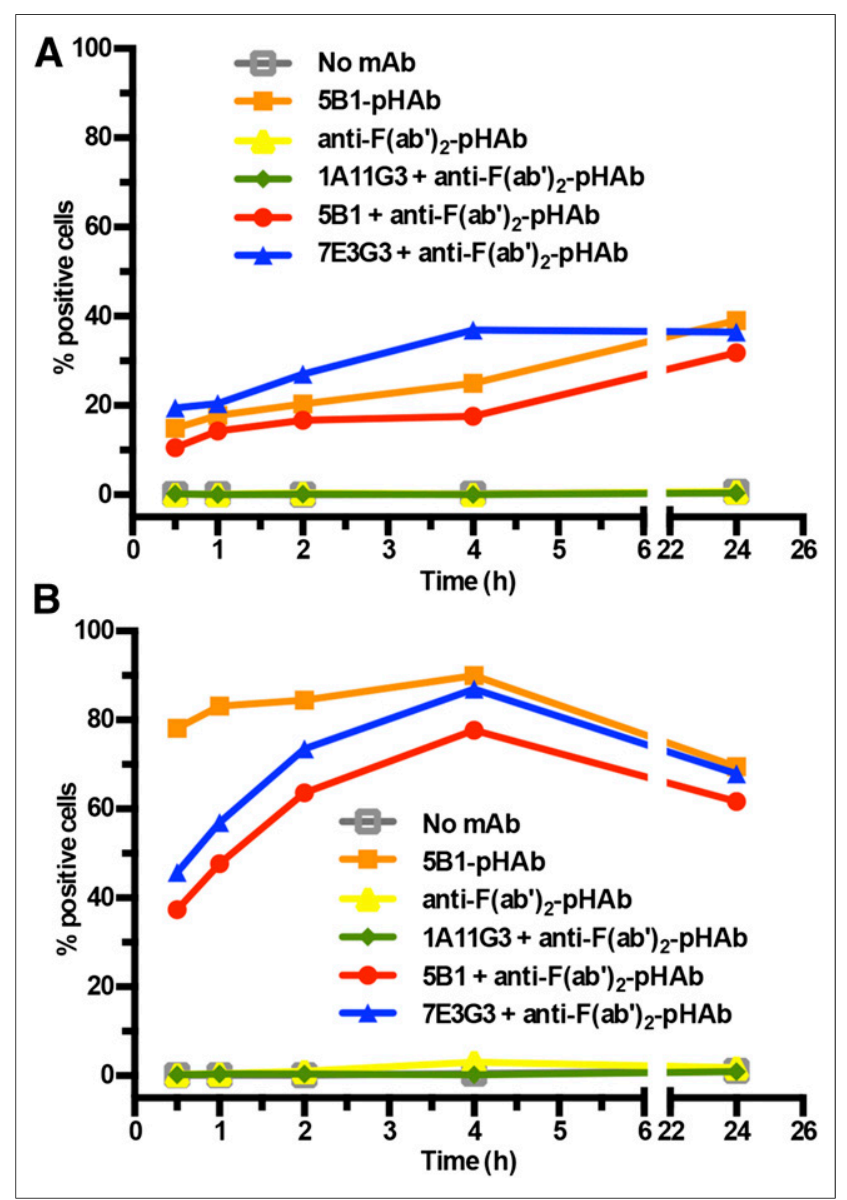

FIGURE 2. Internalization of anti-CA19.9 mAbs and control mAbs labeled directly or indirectly with $\mathrm{pH}$-sensitive dye as determined by flow cytometry is shown for BxPC3 (A) and Capan-2 (B) cell lines. 
BxPC3, Capan-2, or Jurkat cells (control) and incubated at $37^{\circ} \mathrm{C}$. Samples were taken at $30 \mathrm{~min}, 1 \mathrm{~h}, 2 \mathrm{~h}, 4 \mathrm{~h}$, and $24 \mathrm{~h}$, and fluorescence was measured by flow cytometry to determine the percentage of positive cells in each sample on a Millipore Guava 96 system using the yellow parameter (Em filter 583/26).

\section{Biodistribution of ${ }^{64} \mathrm{Cu}-\mathrm{NOTA}-\mathrm{PEG}_{7}-\mathrm{Tz}$ and ${ }^{64} \mathrm{Cu}-\mathrm{NOTA}-\mathrm{Tz}$}

The biodistribution of the radiotracers was determined as previously described (10) in female, athymic nude mice $(n=4)$ with BxPC3 subcutaneous xenografts (right flank, $\sim 200 \mathrm{~mm}^{3}$ ) (Table 1; Supplemental Tables 1 and 2). Mice were randomized and injected via the tail vein with $5 \mathrm{~B} 1-\mathrm{TCO}(200 \mu \mathrm{g}$ in $200 \mu \mathrm{L}$ of $0.9 \%$ saline $)$. After 48,72 , or $120 \mathrm{~h}$, the mice were injected with ${ }^{64} \mathrm{Cu}-\mathrm{NOTA}-\mathrm{PEG}_{7}-\mathrm{Tz}$ $(14.9 \pm 0.5 \mathrm{MBq}[403 \pm 14 \mu \mathrm{Ci}])$ or ${ }^{64} \mathrm{Cu}-\mathrm{NOTA}-\mathrm{Tz}(16.1 \pm 0.3 \mathrm{MBq}$ [436 $\pm 9 \mu \mathrm{Ci}$ ]) in $200 \mu \mathrm{L}$ of $0.9 \%$ sterile saline via the lateral tail vein.

\section{In Vivo PET Imaging with ${ }^{64} \mathrm{Cu}-\mathrm{NOTA}^{-} \mathrm{PEG}_{7}-\mathrm{Tz}$ and ${ }^{64} \mathrm{Cu}-\mathrm{NOTA}-\mathrm{Tz}$}

Where possible, mice were used for both imaging and biodistribution studies to reduce the number of mice required, and the same range of activity $(9.2-13.0 \mathrm{MBq}$ [250-350 $\mu \mathrm{Ci}])$ and moles $(0.7-1.0 \mathrm{nmol})$ of each component was used for all experiments. In control experiments, identical procedures were performed in mice $(n=3)$ that were given nonspecific IgG-TCO rather than 5B1-TCO. Additional details regarding the image acquisition and processing may be found in the supplemental data.

\section{Dosimetry}

The biodistribution data for the ${ }^{64} \mathrm{Cu}-\mathrm{NOTA}-\mathrm{PEG}_{7}-\mathrm{Tz}$ pretargeting system described in this investigation and the biodistribution data for the previously reported ${ }^{89} \mathrm{Zr}$-DFO-5B1 (9) radioimmunoconjugate were expressed to determine the mean organ-absorbed doses and effective dose in $\mathrm{rad} / \mathrm{MBq}$ and $\mathrm{rem} / \mathrm{MBq}$, with $\mathrm{rad} / \mathrm{mCi}$ and $\mathrm{rem} / \mathrm{mCi}$, respectively, in parentheses, as previously described (Table 2) (11).

\section{In Vivo PET and PET/CT Imaging with ${ }^{64} \mathrm{Cu}-\mathrm{NOTA}^{-P_{E}} \mathrm{G}_{7}-\mathrm{Tz}$ in Orthotopic Model}

These studies were performed similarly to those described above, and details may be found in the supplemental data.

\section{Ex Vivo Analysis of Capan-2 Orthotopic Xenografts}

Autoradiography and immunohistochemistry were performed to demonstrate the specificity of the pretargeted radiotracer as previously described $(9,10)$.

\section{Statistical Analysis}

An unpaired, 2-tailed Student $t$ test was used to analyze the data. In all cases, a 95\% confidence level $(P<0.05)$ was considered to represent a statistical difference in the data.

\section{RESULTS}

\section{Preparation of Pretargeting Components}

TCO was successfully conjugated to $5 \mathrm{~B} 1$ using a previously described method (10). The radioligand precursor NOTA-PEG $7^{-}$ $\mathrm{Tz}$ was synthesized in $49 \%$ cumulative yield from commercially available Tz-NHS via 3 sequential reactions (Supplemental Fig. 1). NOTA-PEG $7-\mathrm{Tz}$ was successfully radiolabeled with ${ }^{64} \mathrm{Cu}$ to generate the ${ }^{64} \mathrm{Cu}-\mathrm{NOTA}-\mathrm{PEG}_{7}-\mathrm{Tz}$ radioligand, which was isolated in a greater than $99 \%$ radioisotope purity, $85.8 \% \pm 9.2 \%$ decay-corrected yield, and specific activity of $10.9 \pm 1.0 \mathrm{MBq} / \mu \mathrm{g}$ $(294 \pm 27 \mu \mathrm{Ci} / \mu \mathrm{g})(12.7 \pm 1.2 \mathrm{GBq} / \mu \mathrm{mol}[343 \pm 32 \mathrm{mCi} / \mu \mathrm{mol}]$; $n=6$ ) (Supplemental Fig. 2). Both radioligands were labeled with high specific activity, and before injection the overall amount of radioligand was adjusted to facilitate the administration of 1.1-1.2 molar equivalents of $\mathrm{Tz}$ relative to $5 \mathrm{~B} 1-\mathrm{TCO}$ that was originally injected into each mouse.

\section{Internalization of 5B1 by BxPC3 and Capan-2 Cells}

To measure the internalization of 5B1 directly, we used a $\mathrm{pH}$ indicating dye that is nonfluorescent at neutral $\mathrm{pH}$ in the medium outside the cell and becomes fluorescent when the antibody is internalized into acidic lysosomes. 5B1 and the antihuman $\mathrm{F}\left(\mathrm{ab}^{\prime}\right)_{2}$ were labeled with a dye-to-antibody ratio of 1.4 and 3.7 , respectively. The results show that CA19.9-bound mAbs-5B1 and 7E3G3 - are internalized within minutes by BxPC3 cells, reaching a peak number of cells with internalized antibody after a few hours (Fig. 2A). The same pattern of internalization was seen with 5B1

\section{TABLE 1}

Biodistribution Data for ${ }^{64} \mathrm{Cu}-\mathrm{NOTA}-\mathrm{PEG}_{7}-\mathrm{Tz}$ and ${ }^{64} \mathrm{Cu}-\mathrm{NOTA}-\mathrm{Tz}$

\begin{tabular}{|c|c|c|c|c|c|}
\hline \multirow[b]{2}{*}{ Organ } & \multicolumn{3}{|c|}{$\begin{array}{c}\text { Time after injection of }{ }^{64} \mathrm{Cu}-\mathrm{NOTA}-\mathrm{PEG}_{7}-\mathrm{Tz} \\
\text { with lag time of } 72 \mathrm{~h} \\
\end{array}$} & \multirow{2}{*}{$\begin{array}{l}\text { Time after injection of } \\
{ }^{64} \mathrm{Cu}-\mathrm{NOTA}-\mathrm{PEG}_{7}-\mathrm{Tz} \\
\text { with lag time } 48 \mathrm{~h}=20 \mathrm{~h}\end{array}$} & \multirow{2}{*}{$\begin{array}{l}\text { Time after injection of }{ }^{64} \mathrm{Cu}- \\
\text { NOTA-Tz with lag time of Lag } \\
\text { time of } 48 \mathrm{~h}=20 \mathrm{~h}\end{array}$} \\
\hline & $4 \mathrm{~h}$ & $12 \mathrm{~h}$ & $20 \mathrm{~h}$ & & \\
\hline Blood & $2.2 \pm 0.3$ & $1.9 \pm 0.4$ & $1.9 \pm 0.3$ & $1.4 \pm 0.1$ & $1.7 \pm 0.3$ \\
\hline Tumor & $3.2 \pm 0.5$ & $4.2 \pm 2.4$ & $8.2 \pm 1.7$ & $3.8 \pm 0.5$ & $7.1 \pm 0.7$ \\
\hline Heart & $0.68 \pm 0.05$ & $0.76 \pm 0.20$ & $0.77 \pm 0.14$ & $0.85 \pm 0.03$ & $1.0 \pm 0.2$ \\
\hline Lungs & $1.3 \pm 0.2$ & $1.2 \pm 0.1$ & $1.0 \pm 0.7$ & $1.1 \pm 0.1$ & $1.4 \pm 0.3$ \\
\hline Liver & $1.4 \pm 0.1$ & $1.3 \pm 0.1$ & $1.4 \pm 0.1$ & $2.7 \pm 0.7$ & $1.8 \pm 0.2$ \\
\hline Spleen & $0.59 \pm 0.08$ & $0.63 \pm 0.07$ & $0.73 \pm 0.10$ & $1.0 \pm 0.3$ & $0.80 \pm 0.05$ \\
\hline Pancreas & $0.30 \pm 0.08$ & $0.30 \pm 0.08$ & $0.40 \pm 0.08$ & $0.23 \pm 0.14$ & $0.24 \pm 0.10$ \\
\hline Stomach & $0.34 \pm 0.09$ & $0.22 \pm 0.15$ & $0.23 \pm 0.03$ & $0.73 \pm 0.12$ & $2.4 \pm 1.2$ \\
\hline Large intestine & $2.5 \pm 0.5$ & $0.91 \pm 0.38$ & $0.50 \pm 0.10$ & $0.51 \pm 0.11$ & $0.64 \pm 0.03$ \\
\hline Small intestine & $0.46 \pm 0.08$ & $0.42 \pm 0.09$ & $0.30 \pm 0.06$ & $2.7 \pm 0.4$ & $1.3 \pm 0.1$ \\
\hline Kidney & $1.9 \pm 0.0$ & $1.9 \pm 0.1$ & $1.8 \pm 0.3$ & $0.15 \pm 0.01$ & $0.20 \pm 0.04$ \\
\hline Muscle & $0.20 \pm 0.03$ & $0.16 \pm 0.03$ & $0.48 \pm 0.40$ & $0.26 \pm 0.02$ & $0.32 \pm 0.05$ \\
\hline Bone & $0.23 \pm 0.04$ & $0.25 \pm 0.05$ & $0.31 \pm 0.07$ & $0.55 \pm 0.09$ & $0.64 \pm 0.11$ \\
\hline
\end{tabular}


TABLE 2

Dosimetry Calculations for Various 5B1-Based PET Imaging Strategies

\begin{tabular}{|c|c|c|}
\hline Target organ* & ${ }^{89} \mathrm{Zr}-\mathrm{DFO}-5 \mathrm{~B} 1^{\dagger}$ & ${ }^{64} \mathrm{Cu}-\mathrm{Tz}-\mathrm{PEG}_{7}$-NOTA pretargeting \\
\hline Adrenals & $0.0600(2.22)$ & $0.0021(0.079)$ \\
\hline Brain & $0.0459(1.70)$ & $0.0022(0.081)$ \\
\hline Breasts & $0.0368(1.36)$ & $0.0019(0.071)$ \\
\hline Gallbladder wall & $0.0576(2.13)$ & $0.0022(0.083)$ \\
\hline Lower large intestine wall & $0.0600(2.22)$ & $0.0040(0.149)$ \\
\hline Small intestine & $0.0568(2.10)$ & $0.0025(0.091)$ \\
\hline Stomach wall & $0.0595(2.20)$ & $0.0022(0.081)$ \\
\hline Upper large intestine wall & $0.0535(1.98)$ & $0.0023(0.086)$ \\
\hline Heart wall & $0.0581(2.15)$ & $0.0022(0.081)$ \\
\hline Kidneys & $0.0773(2.86)$ & $0.0020(0.073)$ \\
\hline Liver & $0.0681(2.52)$ & $0.0013(0.047)$ \\
\hline Lungs & $0.0681(2.52)$ & $0.0011(0.041)$ \\
\hline Muscle & $0.0430(1.59)$ & $0.0008(0.031)$ \\
\hline Ovaries & 0.0535 (1.98) & $0.0024(0.087)$ \\
\hline Pancreas & $0.0611(2.26)$ & $0.0022(0.083)$ \\
\hline Red marrow & $0.1084(4.01)$ & $0.0017(0.064)$ \\
\hline Osteogenic cells & $0.1373(5.08)$ & $0.0047(0.173)$ \\
\hline Skin & $0.0316(1.17)$ & $0.0018(0.065)$ \\
\hline Spleen & $0.1000(3.70)$ & 0.0007 (0.025) \\
\hline Testes & $0.0408(1.51)$ & $0.0021(0.076)$ \\
\hline Thymus & $0.0462(1.71)$ & $0.0020(0.075)$ \\
\hline Thyroid & 0.0457 (1.69) & $0.0021(0.077)$ \\
\hline Bladder wall & $0.0503(1.86)$ & $0.0023(0.086)$ \\
\hline Uterus & $0.0538(1.99)$ & $0.0024(0.088)$ \\
\hline Total body & $0.0503(1.86)$ & $0.0021(0.077)$ \\
\hline Effective dose & $0.0546(2.02)$ & $0.0021(0.079)$ \\
\hline
\end{tabular}

*Mean organ-absorbed doses and effective dose are expressed in rad/MBq and rem/MBq, respectively, with $\mathrm{rad} / \mathrm{mCi}$ and $\mathrm{rem} / \mathrm{mCi}$, respectively, in parentheses.

${ }^{\dagger}$ Data originally reported in Viola-Villegas et al. (9).

independent of whether it was labeled directly with the $\mathrm{pH}$-sensitive dye or indirectly via a pHAb-conjugated $\mathrm{F}\left(\mathrm{ab}^{\prime}\right)_{2}$ fragment. 7E3G3 showed similar internalization kinetics whereas the secondary $\mathrm{F}\left(\mathrm{ab}^{\prime}\right)_{2}$ alone and an antibody specific to globo $\mathrm{H}$ - which is not present on these cells-showed no internalization. A similar pattern of internalization was found with Capan-2 cells (Fig. 2B). However, the internalization occurs more rapidly, and a higher percentage of cells was found to have internalized the antiCA19.9 mAbs after only $4 \mathrm{~h}$. Interestingly, a decline in the number of cells with internalized mAb was found after $24 \mathrm{~h}$. As expected, no internalization of 5B1 was detected with Jurkat cells, which do not express the CA19.9 antigen (data not shown).

\section{Biodistribution and In Vivo PET Imaging of ${ }^{64} \mathrm{Cu}-\mathrm{NOTA}-\mathrm{PEG}_{7}-\mathrm{Tz}$ and ${ }^{64} \mathrm{Cu}-\mathrm{NOTA}-\mathrm{Tz}$}

Biodistribution and PET imaging studies were performed concurrently to determine the optimal accumulation interval between the injection of 5B1-TCO and the administration of the tetrazine radioligand as well as to compare the pharmacokinetics of the 2 radioligands. On the basis of previously reported studies with ${ }^{89} \mathrm{Zr}-\mathrm{DFO}-5 \mathrm{~B} 1$ and pilot studies with 5B1-TCO, initial experiments were conducted using a $200-\mu \mathrm{g}$ injection of $5 \mathrm{~B} 1-\mathrm{TCO}$ and a 48-h accumulation interval between the injection of the 2 components. Serial PET imaging showed increasing uptake in the tumor over time for both tracers (Supplemental Fig. 3). The biodistribution data indicated that uptake in the tumor $20 \mathrm{~h}$ after administration of the radioligand was higher with ${ }^{64} \mathrm{Cu}-\mathrm{NOTA}-\mathrm{Tz}$ than with ${ }^{64} \mathrm{Cu}-\mathrm{NOTA}-\mathrm{PEG}_{7}-\mathrm{Tz}$, leading to better tumor-to-tissue ratios with ${ }^{64} \mathrm{Cu}-\mathrm{NOTA}-\mathrm{Tz}$ (Table 1; Supplemental Table 1). Although the data for both radioligands were promising, the background was higher than expected, and as a result, we concluded that $48 \mathrm{~h}$ was not time enough for the 5B1-TCO immunoconjugate to sufficiently clear from the blood.

The lag time was then increased to $72 \mathrm{~h}$, and both serial PET imaging (Fig. 3) and a more thorough biodistribution study with ${ }^{64} \mathrm{Cu}-\mathrm{NOTA}-\mathrm{PEG}_{7}-\mathrm{Tz}$ were performed (Table 1; Supplemental Table 1). Tomographic slices of representative mice injected with ${ }^{64} \mathrm{Cu}-\mathrm{NOTA}-\mathrm{PEG}_{7}-\mathrm{Tz}$ or ${ }^{64} \mathrm{Cu}-\mathrm{NOTA}-\mathrm{Tz}$ are shown in Figure 3, indicating that the uptake in the tumor was rapid for both radioligands and that the tumors could be clearly delineated just $6 \mathrm{~h}$ 


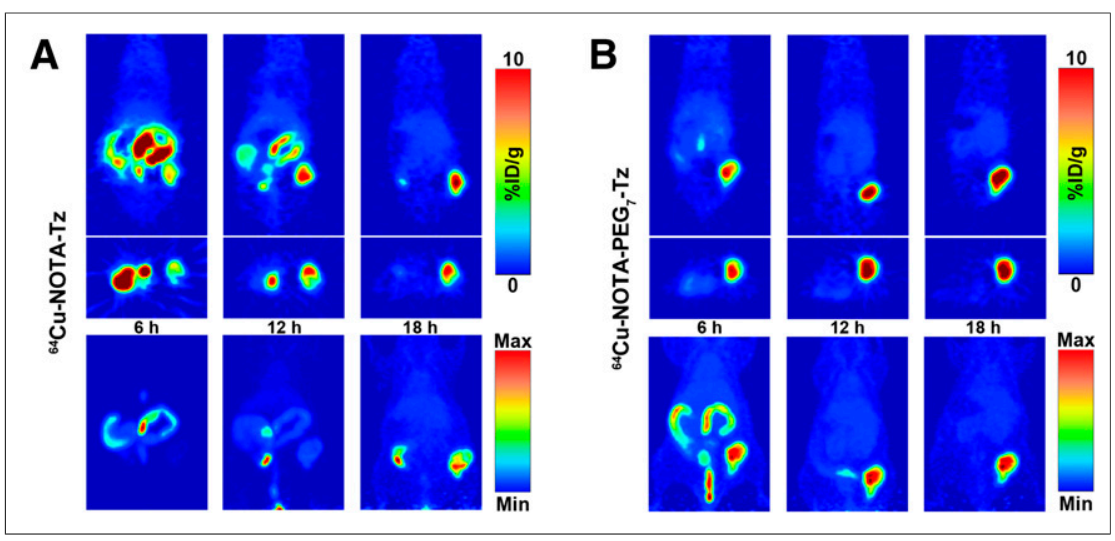

FIGURE 3. Serial PET imaging of mice bearing subcutaneous $B \times P C 3$ xenografts on right flank that were injected with either ${ }^{64} \mathrm{Cu}-\mathrm{NOTA}-\mathrm{Tz}(\mathrm{A})$ or ${ }^{64} \mathrm{Cu}-\mathrm{NOTA}-\mathrm{PEG}_{7}-\mathrm{Tz}$ (B) $72 \mathrm{~h}$ after injection of 5B1-TCO. Tomographic slices bisecting tumor (top) and maximum-intensity projections (bottom) are shown for same representative mice. $\% \mathrm{ID} / \mathrm{g}=$ percentage injected dose/gram; Max = maximum; Min $=$ minimum.

after injection of the tracer. Although the degree of the uptake of the tracers in the tumors was approximately the same at any given time point, the maximum-intensity projections show that the tumorto-background contrast is much better with ${ }^{64} \mathrm{Cu}-\mathrm{NOTA}-\mathrm{PEG}_{7}-\mathrm{Tz}$ at earlier time points (Fig. 3B; Supplemental Fig. 4). The pharmacokinetic advantage imparted by the addition of the $\mathrm{PEG}_{7}$ linker is clear to see, because ${ }^{64} \mathrm{Cu}-\mathrm{NOTA}-\mathrm{Tz}$ is retained in the digestive tract much longer than ${ }^{64} \mathrm{Cu}-\mathrm{NOTA}-\mathrm{PEG}_{7}-\mathrm{Tz}$. In addition, biodistribution data showed that the activity concentration in the tumors was essentially the same for both tracers $20 \mathrm{~h}$ after the administration of the radioligands (Table 1). An additional biodistribution experiment was performed in the same manner as described above to determine whether a 120-h accumulation interval was feasible for pretargeting with ${ }^{64} \mathrm{Cu}-\mathrm{NOTA}-\mathrm{PEG}_{7}-\mathrm{Tz}$ (Supplemental Table 2). In this case, the uptake of the tracer reached only $2.0 \pm 0.7$ percentage

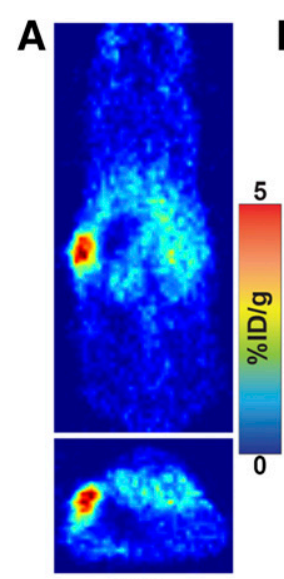

$20 \mathrm{~h}$

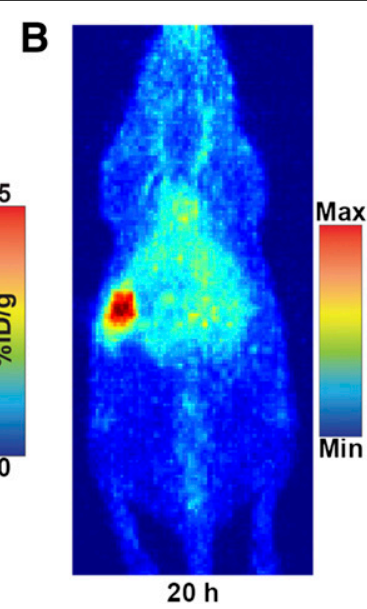

$20 \mathrm{~h}$

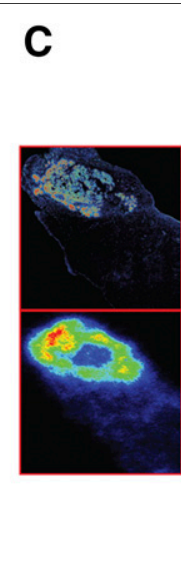

FIGURE 4. PET and PET/CT imaging of representative mouse with orthotopic Capan-2 xenograft in body of pancreas that was injected with 5B1-TCO followed by ${ }^{64} \mathrm{Cu}-\mathrm{NOTA}-\mathrm{PEG}_{7}-\mathrm{Tz} 72 \mathrm{~h}$ later. Tomographic slices bisecting tumor $(A)$ and maximum-intensity projection $(B)$ from representative mouse are shown. Also shown is PET/CT scan of same mouse (C, right) and corresponding anti-CA19.9 immunohistochemistry (C, top left) and autoradiography (C, bottom left). $\% \mathrm{ID} / \mathrm{g}=$ percentage injected dose/gram; Max = maximum; Min = minimum. injected dose per gram at $20 \mathrm{~h}$, suggesting that a 72 -h interval likely provides the best combination of blood clearance, chemical stability, and surface persistence of the 5B1-TCO construct.

Finally, it was critical to demonstrate that the uptake of the radiotracer in the BxPC3 xenografts was directly related to the specificity of the 5B1-TCO immunoconjugate for its CA19.9 antigen. To this end, an imaging experiment was performed in which an isotype control IgG-TCO construct was substituted for 5B1-TCO. Athymic nude mice bearing subcutaneous $\mathrm{BxPC} 3$ xenografts were administered IgG-TCO $(200 \mu \mathrm{g})$ and ${ }^{64} \mathrm{Cu}-\mathrm{NOTA}-\mathrm{PEG}_{7}-\mathrm{Tz}(14.8-18.5 \mathrm{MBq}$ [400-500 $\mu \mathrm{Ci}]$ ) separated by a $72-\mathrm{h}$ accumulation interval. Serial PET imaging subsequently revealed that the activity concentrations of the radioligand in the tumors were negligible $(<1$ percentage injected dose per gram), thus clearly illustrating that the accumulation of the ${ }^{64} \mathrm{Cu}-\mathrm{Tz}$ in the tumor is dependent on the use of the CA19.9targeting immunoconjugate (Supplemental Fig. 5).

\section{Dosimetry}

We assessed the radiation dose associated with this pretargeting strategy using the biodistribution data for the ${ }^{64} \mathrm{Cu}-\mathrm{NOTA}-\mathrm{PEG}_{7}-\mathrm{Tz} /$ $5 \mathrm{~B} 1-\mathrm{TCO}$ pretargeting methodology and the previously published data obtained for ${ }^{89} \mathrm{Zr}-\mathrm{DFO}-5 \mathrm{~B} 1$ (Table 2). As expected, the ${ }^{64} \mathrm{Cu}-$ based pretargeting strategy resulted in a significant reduction in radiation exposure, compared with the ${ }^{89} \mathrm{Zr}-\mathrm{DFO}-5 \mathrm{~B} 1$ radioimmunoconjugate, lowering the total effective dose by over 25 -fold. This dosimetric advantage is even more pronounced when the mean organ-absorbed doses to some specific tissues are considered, most notably the liver, lungs, red marrow, and spleen. In contrast-and not surprisingly, given the elimination pathway of the radioligand - the tissue for which the pretargeting strategy provided the least dosimetric relief was the lower large intestine wall, which was merely an approximately 15 -fold reduction.

\section{PET, PET/CT, and Ex Vivo Analysis of ${ }^{64} \mathrm{Cu}-\mathrm{NOTA}-\mathrm{PEG}_{7}-\mathrm{Tz}$ in Orthotopic Model}

Because BxPC3 cells do not shed CA19.9 into the blood, whereas nearly all human PDAC patients do, we tested the optimized pretargeting method in a model that more accurately recapitulates human disease. An orthotopic Capan-2 xenograft model was used because, in addition to the tumor being induced in an anatomically correct position, Capan-2 xenografts are known to shed large amounts of CA19.9 (12). PET/CT imaging using the optimized strategy with ${ }^{64} \mathrm{Cu}-\mathrm{NOTA}-\mathrm{PEG}_{7}-\mathrm{Tz}$ yielded high-quality images, clearly delineating Capan-2 xenografts in the body of the pancreas (Fig. 4). The uptake of the tracer was, unsurprisingly, 
slightly decreased relative the BxPC3 subcutaneous xenografts, and increased retention in the blood was also apparent in the maximum-intensity projections (Fig. 4B). To confirm uptake at the site of the orthotopic tumor and to demonstrate specificity of the tracer, autoradiography and immunohistochemistry were performed (Fig. 4C). Tumor tissue and the surrounding healthy pancreas were analyzed, showing that the CA19.9 expression pattern was consistent with the uptake of the radioligand as visualized in the autoradiography.

\section{DISCUSSION}

Evaluation of PDAC biomarkers as targets for immuno-PET imaging or immunotherapy have achieved varying degrees of success (3). 5B1 and ${ }^{89} \mathrm{Zr}$-DFO-5B1 are both currently undergoing clinical translation at Memorial Sloan Kettering Cancer Center as a potential therapeutic and PET imaging agent, respectively. Although preclinical results with ${ }^{89} \mathrm{Zr}$-DFO-5B1 were impressive, it stands to reason that the secreted CA19.9 will ultimately lead to increased radiation dose to healthy tissues. In fact, in the context of shed antigen ${ }^{89} \mathrm{Zr}$-DFO-5B1 uptake was significantly reduced in the tumor and retention in nontarget tissues, especially the liver and spleen, was increased. In cases in which limited PET imaging procedures are necessary, this is unlikely to pose a problem. However, the development of a second-generation, pretargeted imaging platform based on 5B1 could both shorten the time between injection of tracer and a patient's imaging time and also reduce patients' exposure in situations requiring repeated PET imaging (i.e., long-term monitoring of treatment response). For those reasons, it seemed that 5B1 would make an excellent candidate for pretargeted PET.

Evidence that 5B1 was internalized into BxPC3 cells insinuated that adapting $5 \mathrm{~B} 1$ to a pretargeting system would be challenging (8). Although internalization is beneficial in some contexts, the prevailing opinion in the literature has been that internalization of the antigen-targeting component would make a pretargeting system unworkable. However, it stands to reason that the rate and extent of internalization of the targeting component as well as several other pharmacokinetic properties of any given system would need to be evaluated to make such an assertion.

To examine the kinetics of 5B1 internalization in PDAC cell lines more directly, we labeled 5B1 and 7E3G3-2 distinct human, antiCA19.9 mAbs - with a $\mathrm{pH}$-sensitive probe that allows detection of internalization in real time. We evaluated the internalization of $5 \mathrm{~B} 1$ using 2 human PDAC cell lines. BxPC3 was chosen because it has been used to evaluate other anti-CA19.9 imaging agents, including ${ }^{89} \mathrm{Zr}$-DFO-5B1. Capan-2 was chosen because it is known to shed physiologically relevant amounts of CA19.9, providing a challenging model in which to evaluate our pretargeting strategy. Interestingly, we found that BxPC3 and Capan-2 cells internalized 5B1, but Capan-2 did so more rapidly and to a greater extent. Differences in the rate of internalization have also been observed with other antigens and cell lines (13), but it remains to be elucidated what contributes to the difference in kinetics and magnitude of internalization-we are still investigating this phenomenon.

With that knowledge in hand, we performed imaging and biodistribution studies. The biodistribution data reported for ${ }^{89} \mathrm{Zr}$-DFO$5 \mathrm{~B} 1$ and the reported biologic half-life of TCO $(14)(\sim 3 \mathrm{~d})$ were used as points of reference to adapt our pretargeting strategy. An accumulation interval of $48 \mathrm{~h}$ between the injection of the 5B1TCO and the radioligand was chosen for initial studies, and the imaging and biodistribution data revealed that although the pretargeting strategy could work quite well-even in a cell line known to internalize the antigen-targeting component-the system needed further optimization. Those initial experiments also suggested that despite the high-activity concentrations of ${ }^{64} \mathrm{Cu}-\mathrm{NOTA}-\mathrm{Tz}$ in tumor tissue, the clearance from nontarget tissues, and especially the digestive tract, was far more rapid with ${ }^{64} \mathrm{Cu}-\mathrm{NOTA}-\mathrm{PEG}_{7}-\mathrm{Tz}$. When the interval between injections was increased to $72 \mathrm{~h}$, the ${ }^{64} \mathrm{Cu}-$ NOTA-PEG ${ }_{7}-\mathrm{Tz}$ was clearly a better choice. The images distinctly showed that, whereas both tracers showed rapid accumulation in the tumor tissues, ${ }^{64} \mathrm{Cu}-\mathrm{NOTA}-\mathrm{PEG}_{7}-\mathrm{Tz}$ cleared significantly more quickly than ${ }^{64} \mathrm{Cu}-\mathrm{NOTA}-\mathrm{Tz}$, clearly delineating the tumor tissue in PET images as early as $6 \mathrm{~h}$ after administration.

Dosimetry calculations were performed to quantify the expected reduction in absorbed radiation dose. At first glance, a comparison between the ${ }^{64} \mathrm{Cu}$-based pretargeting methodology and the antibody directly labeled with ${ }^{64} \mathrm{Cu}$ seems most appropriate. However, we believe that ${ }^{89} \mathrm{Zr}$-DFO-5B1 is more relevant, as the ${ }^{89} \mathrm{Zr}$-labeled radioimmunoconjugate is currently undergoing clinical translation. In this model, the advantage gained by pretargeting is obvious, leading to a greater than 25-fold decrease in absorbed dose for the total body and at least a 15 -fold decrease for each tissue.

As a final test of the viability of the anti-CA19.9 pretargeting system in PDAC, we evaluated it in an orthotopic Capan-2 xenograft model. This model provides a better recapitulation of human disease and presents a more challenging task, as the tumor is initiated in an anatomically appropriate position using Capan- 2 cells that both shed a significant amount of CA19.9 and rapidly internalize 5B1. However, using our optimized approach, we were able to clearly delineate the tumor in the pancreas using PET and PET/CT. Furthermore, on resection of the tumor and surrounding healthy pancreas, we were able to confirm the specificity via autoradiography and anti-CA19.9 immunohistochemistry. The decreased tumor uptake and increased retention in the blood were to be expected but only slightly detracted from the image quality. Strategies to reduce the retention of pretargeted radioligands in the blood-such as the use of clearing agents - have been reported (15). In a clinical setting, a clearing agent could be necessary, because the amount of 5B1-TCO that is retained in the blood will likely be higher in humans. Also, the amount of circulating CA19.9 may also be a determinant of whether a clearing agent is ultimately necessary to achieve good image contrast. Fortuitously, CA19.9 is monitored in essentially all patients with PDAC, which may allow for personalized imaging strategies on a patient-to-patient basis. These possibilities are currently being investigated in our laboratory.

\section{CONCLUSION}

We have demonstrated, to the best of our knowledge, the first successful pretargeted imaging of an antigen that is both secreted and prone to internalization. In doing so, we have also improved on the pharmacokinetics of a previously reported pretargeting radioligand. Our results challenge the notion that surface persistence is an absolute prerequisite for the development of a successful pretargeting methodology. Although it is likely that our strategy is possible due to some amount of surface persistence, we are also investigating the possibility that the tracer is reaching its target inside the cell.

It is conceivable that the pretargeting strategy described here could eventually be useful in several clinical situations, ranging from patient stratification for antibody-drug conjugate treatment to PET imaging for staging or treatment monitoring. Strategies for 
improving image quality and overall performance in the context of secreted and internalizing antigens have been reported and are being pursued in our laboratory for further optimization.

\section{DISCLOSURE}

The costs of publication of this article were defrayed in part by the payment of page charges. Therefore, and solely to indicate this fact, this article is hereby marked "advertisement" in accordance with 18 USC section 1734. The MSKCC Small Animal Imaging Core Facility and the Radiochemistry and Molecular Imaging Probe core were supported in part by NIH grant P30 CA08748. This study was also supported in part by NIH grants 1F32CA180452-01A1, 5R25CA096945-09, 2R42CA128362, HHSN261201300060C, 1K99CA178205-01A1, and 4R00CA178205-02). Wolfgang W. Scholz is an employee of Mabvax and has an equity interest. No other potential conflict of interest relevant to this article was reported.

\section{ACKNOWLEDGMENTS}

We thank the staff of the MSKCC Small Animal Imaging Core Facility and the Radiochemistry and Molecular Imaging Probe core.

\section{REFERENCES}

1. Rahib L, Smith BD, Aizenberg R, Rosenzweig AB, Fleshman JM, Matrisian LM. Projecting cancer incidence and deaths to 2030: the unexpected burden of thyroid, liver, and pancreas cancers in the United States. Cancer Res. 2014;74:2913-2921.

2. Koyama K, Okamura T, Kawabe J, et al. Diagnostic usefulness of FDG PET for pancreatic mass lesions. Ann Nucl Med. 2001;15:217-224.

3. Dimastromatteo J, Houghton JL, Lewis JS, Kelly KA. Challenges of pancreatic cancer. Cancer J. 2015;21:188-193.
4. Kannagi R, Izawa M, Koike T, Miyazaki K, Kimura N. Carbohydrate-mediated cell adhesion in cancer metastasis and angiogenesis. Cancer Sci. 2004;95:377-384.

5. Loy TS, Sharp SC, Andershock CJ, Craig SB. Distribution of CA 19-9 in adenocarcinomas and transitional cell carcinomas: an immunohistochemical study of 527 cases. Am J Clin Pathol. 1993;99:726-728.

6. Yamaguchi K, Enjoji M, Tsuneyoshi M. Pancreatoduodenal carcinoma: a clinicopathologic study of 304 patients and immunohistochemical observation for CEA and CA19-9. J Surg Oncol. 1991;47:148-154.

7. Girgis MD, Kenanova V, Olafsen T, McCabe KE, Wu AM, Tomlinson JS. AntiCA19-9 diabody as a PET imaging probe for pancreas cancer. J Surg Res. 2011;170: 169-178.

8. Sawada R, Sun SM, Wu X, et al. Human monoclonal antibodies to sialyl-Lewis (CA19.9) with potent CDC, ADCC, and antitumor activity. Clin Cancer Res. 2011;17:1024-1032.

9. Viola-Villegas NT, Rice SL, Carlin S, et al. Applying PET to broaden the diagnostic utility of the clinically validated CA19.9 serum biomarker for oncology. J Nucl Med. 2013;54:1876-1882.

10. Zeglis BM, Sevak KK, Reiner T, et al. A pretargeted PET imaging strategy based on bioorthogonal Diels-Alder click chemistry. J Nucl Med. 2013;54:1389-1396.

11. Stabin MG, Sparks RB, Crowe E. OLINDA/EXM: the second-generation personal computer software for internal dose assessment in nuclear medicine. $\mathrm{J} \mathrm{Nucl}$ Med. 2005;46:1023-1027.

12. Takamori H, Hiraoka T, Yamamoto T. Expression of tumor-associated carbohydrate antigens correlates with hepatic metastasis of pancreatic cancer: clinical and experimental studies. Hepatogastroenterology. 1996;43:748-755.

13. Wargalla UC, Reisfeld RA. Rate of internalization of an immunotoxin correlates with cytotoxic activity against human tumor cells. Proc Natl Acad Sci USA. 1989; 86:5146-5150.

14. Devaraj NK, Thurber GM, Keliher EJ, Marinelli B, Weissleder R. Reactive polymer enables efficient in vivo bioorthogonal chemistry. Proc Natl Acad Sci USA. 2012;109:4762-4767.

15. Rossin R, Lappchen T, van den Bosch SM, Laforest R, Robillard MS. Diels-Alder reaction for tumor pretargeting: in vivo chemistry can boost tumor radiation dose compared with directly labeled antibody. J Nucl Med. 2013;54:1989-1995. 